\title{
Platón y el mito de las amazonas*
}

\author{
Víctor Hugo Méndez Aguirre
}

A

lo largo de todo el mundo pueden detectarse mitos según los cuales las mujeres o bien dominaron o bien tuvieron los mismos derechos que los hombres. Bachofen y sus seguidores consideraron que estas historias reflejaban la realidad y postularon que las primeras formaciones económico-sociales fueron matriarcales. Actualmente aún se discute si realmente existieron tales matriarcados. Pero no pocos antropólogos, Leacock, Gough y Borun entre ellos, descartan tal hipótesis. ${ }^{1}$

Ante tal perspectiva, algunos de los antropólogos que dudan de la existencia real del matriarcado primitivo postulan que los mitos que aluden a él no pretenden describir un estado de cosas anterior, sino legitimar el orden presente haciendo notar que cuando las mujeres gobernaron a los hombres condujeron al caos a la sociedad. Joan Bamberger lee así los mitos sudamericanos del matriarcado. ${ }^{2} \mathrm{Y}$ no pocos filólogos han incorporado esta interpretación en su tratamiento de la modalidad ateniense del mito griego de las amazonas. ${ }^{3}$

Únicamente por mencionar algunos trabajos surgidos durante la última década se puede señalar que Tyrrell, Taboada y Just consideran que el mito

* Ponencia presentada en el VIII Congreso Nacional de Filosofia celebrado en la Universidad Autónoma de Aguascalientes del 7 al 10 de noviembre de 1995.

' Cf. Paula Webster y Esther Newton, "Matriarcado: enigma y paradigma", en Olivia Harris y Kate Yung, eds., Antropología y feminismo. Trad. de Fabián Prieto. Barcelona, Anagrama, 1979, pp. 83-106.

${ }^{2} C f$. Joan Bamberger, "El mito del matriarcado: ¿por qué gobiernan los hombres en las sociedades primitivas?", en Olivia Harris y Kate Yung, eds., op. cit. Trad. de Nuria Pubill, pp. 63-81.

${ }^{3}$ Cf. G. H. Taboada, "En torno a las amazonas: mito, etnografia, utopía y mujeres", en Nova Tellvs, núm. 8, 1990, pp. 61-70; William Blake Tyrrell, Las amazonas. Un estudio de los mitos atentenses. Trad. de Juan José Utrilla. México, FCE, 1989, y Roger Just, Women in Athenian Law and Life. Nueva York, Routledge, 1991. 
de las amazonas fue empleado por los atenienses como una estrategia ideológica tendiente a legitimar la existencia de jerarquías en general, y del patriarcado en particular. Esta historia funcionaría como una especie de reducción al absurdo que ilustraría el caos que imperaría si las mujeres no estuvieran subordinadas a los hombres.

Quizá la lectura anterior sea atinada en lo atinente a Lisias e Isócrates. Sin embargo, algunos de los seguidores de esta línea se inclinan a atribuir tal propósito al otro gran contemporáneo de estos autores que escribe sobre las amazonas: Platón. Tyrrell acepta que:

Platón deseaba suprimir el matrimonio y la familia porque los consideraba causa de múltiples males para la sociedad. La familia dividía a la comunidad en unidades individuales, en exclusiva competencia. Al tener mujeres e hijos en común, los Guardianes quedarian libres de mantener una familia y dinero para la mujer y los sirvientes. El matriarcado y la utopía liberarian a las mujeres del matrimonio patriarcal; el uno, para justificarlo, la otra para librarse de sus males. ${ }^{4}$

Pero enfatiza que “[...] Platón no es feminista [...] Las ideas de Platón sobre las mujeres se siguen de su argumento y tal vez de su desinterés en sus vidas". 5

Page duBois ya había sostenido antes la interpretación de Tyrrell. Para ella las amazonas al igual que los centauros son seres mitológicos creados para expresar las ideas griegas sobre el matrimonio y la civilización. ${ }^{6}$

Los trabajos de Tyrrell y duBois están tan bien documentados y sus argumentaciones son tan coherentes que están destinados a ser fuentes fundamentales en los estudios posteriores acerca de las amazonas. Sin embargo, adolecen del defecto de que cuando hablan de Platón prescinden de los diálogos que mencionan a las amazonas y recurren a otros en los que éstas brillan por su ausencia. Y si se corrige esto resulta una visión muy diferente del tratamiento platónico del mito.

El Menéxeno es el primer diálogo que alude a las mujeres guerreras. El epitafio formulado ahí por Aspasia, al igual que el de Lisias (4-6) o el Panegírico (68-70) de Isócrates, alaba a los antiguos atenienses por haberlas derrotado cuando sin ningún derecho pretendían invadir el Ática (239 b). En general se considera que aquí Platón pretende satirizar a ambos oradores y

${ }^{4}$ W. B. Tyrrell, op. cit., p. 77.

${ }^{5}$ Ibid., pp. 77.78

'Page duBois, "On Horse/Men, Amazons and Endogamy", en Arethusa 12, núm. 1, 1979, pp. 35-49. 
en particular las ideas imperialistas de Isócrates. ¿Intentará también mofarse del pensamiento patriarcal de éstos? No es prudente responder tal interrogante con la sola evidencia de una obra satírica. Pero esto sí se puede hacer cuando se maneja otra tan adusta como las Leyes.

En muchos sentidos los diálogos de senectud adoptan la postura tradicional griega acerca de los mitos. De acuerdo con la epistemología poética imperante en tal tradición el conocimiento de las cosas en general y de la historia en particular es patrimonio de las divinidades, que si lo desean pueden compartirlo con los mortales. Pero ellas también pueden optar por engañarnos. Por esto tanto poetas -Homero, Píndaro, etcétera-como filósofos - Parménides, Empédocles, etcétera- se encomiendan a las musas antes de transmitir su mensaje a los hombres y a las mujeres. La Teogonía incluso inicia invocando a las musas helicónides que fueron maestras de Hesíodo y quienes le comunicaron "Pastores agrestes, tristes oprobios, vientres tan sólo, sabemos decir muchas mentiras a verdad parecidas, mas sabemos tam. bién, si queremos, cantar la verdad". 7

Platón, al igual que Hesiodo, cree que los mitos de los poetas contienen grandes cantidades de mentiras. Pero sobre todo en su senectud creyó que algunas de estas historias decían la verdad. Y el ateniense que protagoniza las Leyes resalta que "[...] el linaje de los poetas, siendo sin duda algo divino e inspirado en sus cantos, alcanza una vez y otra, con la ayuda de ciertas Gracias y Musas, muchas cosas de las realmente sucedidas".${ }^{8}$ Notablemente aqui se alude a los mitos acerca de la guerra relatada en la lliada. Y felizmente gracias a que Schliemann tuvo 2400 años después de Platón la misma intuición que éste, las ciudades de Troya fueron rescatadas.

La misma categoria que el discipulo de Sócrates concede al mito de Troya también la otorga al de las amazonas. Y cuando aquél alude otra vez a las amazonas lo hace para justificar su teoría de que en un Estado bien goberna. do las mujeres deben de compartir algunas de las obligaciones militares atribuidas tradicionalmente a los hombres. El ateniense que protagoniza las Leyes indica que defiende sus ideas pro igualitarias

[...] pues me he persuadido de ello al oír antiguos mitos y aún ahora saber que en los países vecinos al Ponto hay, como quien dice, incontables miriadas de mujeres, las liamadas sauromátides, a las cuales la comunidad con los varones no sólo en el manejo de los caballos, sino

${ }^{7}$ Hesíodo, Teogonia. Trad. de Paola Vianello. México, unam, 1978, vv. 26-28.

* Platón, Leyes. Trad. de José Manuel Pabón y Manuel Fernández-Galiano. Madrid, Instituto de Estudios Políticos, 1960, $682 \mathrm{c}$. 
también de los arcos y de las demás armas ha sido prescrita sin distinciones para que se ejerciten sin distinciones también. ${ }^{?}$

Heródoto relata que las sauromátides eran descendientes de las amazonas y de los escitas (IV 110-117); el tratado hipocrático Aires, aguas y lugares precisa que las costumbres de aquel pueblo eran las atribuidas tradicionalmente a las de la etnia de las míticas mujeres guerreras (17). Y el ateniense de las Leyes insiste en que las mujeres del Estado que diseña deberían de poder imitar en caso de necesidad a las sauromátides y/o a las amazonas (806 b-c).

Platón sostiene que algunas mujeres son aptas y/o pueden ser entrenadas para la guerra en la República, Timeo, Critias y Leyes. Y el que en su última obra reconozca que tal idea está inspirada parcialmente en el mito de las amazonas conduce a concluir que la creencia en la posibilidad de que las mujeres sean amas de casa o guerreras, en que nada hay en su naturaleza que las determine a acoplarse a una determinada organización patriarcal de la sociedad, nunca abandonó al autor de la República.

Sucintamente, el mito de las amazonas es empleado por Platón para defender sus últimas concepciones antropológicas igualitarias, para sostener que las conductas y actitudes que las diferentes sociedades exigen de sus mujeres dependen más de la cultura que de una supuesta "naturaleza femenina"

${ }^{9}$ Ibid., 804 e. 